\title{
Statistical investigation regarding clinical and therapeutic aspects of class III Angle anomalies
}

\author{
Investigații statistice privind aspectele clinice şi terapeutice ale anomalilor \\ de clasa a III-a Angle
}

\author{
Mioara V. Decusară', Lorrena Igescu², Daniela Cornea', Delia Daragiu³, \\ Maximilian Ilea ${ }^{4}$, Anne-Marie Rauten ${ }^{5}$ \\ ${ }^{1}$ Departamentul de Medicină Dentară, Facultatea de Medicină și Farmacie, \\ Universitatea „Dunărea de Jos", Galați, România \\ ${ }^{2}$ Spitalul Clinic de Urgență, Târgu-Mureș, România \\ ${ }^{3}$ Facultate de Medicină Dentară, Universitatea "Titu Maiorescu“, Bucureşti, România \\ ${ }^{4}$ Facultatea de Medicină Dentară, Universitatea de Medicină, Farmacie, \\ Științe și Tehnologie „,George Emil Palade", Târgu Mureş, România \\ ${ }^{5}$ Facultatea de Medicină Dentară, Universitatea de Medicină și Farmacie, Craiova, România
}

\begin{abstract}
Introduction. The treatment of dento-maxillary anomalies requires knowledge of the etiological factors involved in the occurrence of diseases and manifestations related to the age, general condition and dento-periodontal status of the patient. Aim and objectives. From the multitude of dento-maxillo-facial anomalies we chose the study of the incidence of class III Angle anomalies, given that it is a dysmorphic entity, with a special multifactorial etiology and various clinical manifestations, dental, functional or skeletal.

Material and method. Depending on the particularities of each clinical case, in order to evaluate a correct diagnosis and establish an effective treatment plan, clinical and paraclinical investigations were performed based on which a statistic on the incidence of class III anomaly was performed on a group of 56 patients, aged 7-45 years, consulted and treated for a period of 18 months.

Results and discussions. In the whole study group ( $\mathrm{N}=410$ patients), a low frequency of clinical cases with class III angle abnormality ( $\mathrm{N}=56$ ) was found, results that were observed with the help of static analysis performed and exemplified by graphical methods.

Conclusions. Although there is a wide range of treatment modalities, from a prophylactic, interceptive and curative point of view, current orthodontic technical advances allow the clinician to offer a quality, individualized orthodontic treatment with favorable aesthetic results and in association with psycho-somatic and social status of the patient.
\end{abstract}

Keywords: class III Angle abnormalities, clinical and paraclinical investigations, orthodontic treatment

REZUMAT
Introducere. Tratamentul anomaliilor dento-maxilare necesită cunoaşterea factorilor etiologici implicaţi în apariţia
bolilor şi manifestările corelate cu vârsta, starea generală şi statusul dento-parodontal ale pacientului.
Scop şi obiective. Din multitudinea de anomalii dento-maxilo-faciale, am ales studiul incidenţei anomaliilor de
clasa a III-a Angle, având în vedere faptul că reprezintă o entitate dismorfică, cu o etiologie plurifactorială deosebită
şi manifestări clinice diverse, dentare, funcţionale sau scheletale.
Material şi metodă. În funcţie de particularităţile fiecărui caz clinic, pentru evaluarea unui diagnostic corect şi
stabilirea unui plan eficient de tratament, s-au realizat investigaţii clinice şi paraclinice pe baza cărora s-a realizat
o statistică privind incidenţa anomaliei de clasei a III-a Angle, pe un lot de 56 pacienţi, cu vârste cuprinse între 7 şi
45 ani, consultaţi şi trataţi pe o perioadă de 18 luni.
Rezultate şi discuțtii. În cadrul întregului lot studiat $(\mathrm{N}=410$ pacienţi), s-a constatat o frecvenţă redusă a cazurilor
clinice ce prezintă anomalie de clasa a III-a Angle $(\mathrm{N}=56)$ rezultate care au fost observate cu ajutorul analizei
statice efectuate şi exemplificate prin metode grafice.
Concluzii. Deşi există o paletă vastă de modalităţi de tratament, din punct de vedere profilactiv, interceptiv şi cura-
tiv, progresele tehnice ortodontice actuale permit clinicianului posibilitatea de a oferi un tratament ortodontic de ca-
litate, individualizat, cu rezultate estetice favorabile şi în asociere cu statusul psiho-somatic şi social al pacientului.

Cuvinte cheie: anomalii de clasa a III-a Angle, investigaţii clinice şi paraclinice, tratament ortodontic 


\section{INTRODUCERE}

Prima clasificare a anomaliilor dento-maxilare, după raporturile ocluzale, a fost propusă de Edward Angle în anul 1899, fiind folosită şi astăzi, datorită simplităţii sale în aplicare. Conform lui Edward H. Angle, relaţia neutrală este atunci când cuspidul mezio-vestibular al primului molar superior articulează cu şanţul intercuspidian al primului molar inferior (1-3). Orice deviere de la această aliniere se încadrează în cele trei clasificări ale anomaliilor, iar aceste categorii sunt următoarele:

- Malocluzia de clasa I - relaţiile molare sunt neutrale, dar există malpoziţii dentare, rotaţii, diasteme sau înghesuiri dento-alveolare.

- Malocluzia de clasa a II-a - cuspidul meziovestibular al primului molar maxilar este situat distal faţă de şanţul intercuspidian al primului molar mandibular. Clasa II este subdivizată astfel:

- Clasa II, diviziunea 1 - cu raporturi distalizate în zona molară şi cu o suprapunere incisivă ,în acoperiş“; când acest raport este unilateral, este denumită subdiviziunea 1 ;

- Clasa II, diviziunea 2 - cu raporturi distalizate în zona molară şi cu o suprapunere incisivă ,acoperită“; când acest raport este unilateral, este denumită subdiviziunea 2;

- Malocluzia de clasa a III-a - cuspidul mezio-vestibular al primului molar superior este situat mezial faţă de şanţul intercuspidian al primului molar inferior. Este împărţită în trei categorii: de conducere forţată, retrognatism maxilar (fals prognatism) şi prognatismul mandibular adevărat $(2,3)$.

Moyers a clasificat etiopatogenia anomaliilor de clasa a III-a astfel: ereditatea, defecte de dezvoltare de origine necunoscută, traumatisme, agenţi fizici, obiceiuri vicioase, boli generale, nutriţia (4). Graber a simplificat această clasificare şi urmăreşte prezenţa a doi factori importanţi: generali (ereditari, congenitali, de mediu, funcţionali şi de postură) şi locali (anomaliile de număr, volum, formă, inserţia anormală a frenurilor, pierderea prematură a dinţilor temporari, persistenţa sau întârzierea de erupţie a dinţilor permanenţi, blocaje în erupţia dinţilor, anchiloze, leziuni carioase sau restaurări odontale incorecte) (5-7).

Diagnosticul anomaliilor dento-maxilare se realizează pe baza examenului clinic şi a examenelor complementare: fotostatic, modele de studiu şi examene radiografice (ortopantomograma, teleradiografie de profil, CBCT) (8). Examenul clinic cuprinde $(3,9-12)$ :

- examenul general (evaluarea dezvoltării somatice şi a personalităţii)

- anamneza (date personale, motivele prezentării, istoricul afecţiunii, antecedente heredocolaterale, antecedente personale generale şi stomatologice)

- motivelor prezentării la consult

- examenului clinic exooral - inspecţie (din normă frontală şi laterală, simetrie facială, proporţia etajelor feţei, treapta labială şi fanta labială, şanţul labio-mentonier, unghiul mandibular), palparea conturului facial şi articulaţiei temporo-mandibulare

- examenul clinic endooral - arcade dentare, alveole, parodonţie, părţi moi, ocluzie dentară

- examenul funcţional - al musculaturii (mandibulare, buze, limbă), al respiraţiei, deglutiţiei, fonaţiei, masticaţiei, fizionomiei

- examenul ocluziei în dinamică

- teste dinamico-funcţionale (de propulsie şi retropulsie mandibulară)

În urma examenelor clinice şi complementare, se stabileşte un plan de tratament în funcţie de vârsta pacientului, perioada de creştere, dentiţie, statusul dento-parodontal şi colaborarea cu echipa stomatologică $(13,14)$. Tratamentul anomaliilor de clasa a III-a poate fi: interceptiv şi profilactic (în perioada dentiţiei de lapte şi a dentiţiei mixte, folosind aparate funcţionale, mobilizabile şi fixe, asociate cu forţe intra- şi extraorale) şi tratament curativ (în dentiţia definitivă, utilizând aparate ortodontice fixe şi tratamentul chirurgical-ortodontic) (15-17).

\section{SCOP ŞI OBIECTIVE}

Din multitudinea de anomalii dento-maxilofaciale am ales studiul incidenţei anomaliilor de clasa a III-a Angle, având în vedere faptul că reprezintă o entitate dismorfică, cu o etiologie plurifactorială deosebită şi manifestări clinice diverse, dentare, funcţionale sau scheletale. Investigaţiile statistice au fost efectuate pe un lot de pacienţi cu anomalii cu rapoarte ocluzale mezializate în plan sagital, cu dentiţie mixtă şi definitivă, care şi-au dat acordul cu privire la participarea la studiu şi la tratamentul ortodontic. 


\section{MATERIAL ŞI METODE}

Studiul efectuat este unul retrospectiv, realizat în perioada noiembrie 2018-martie 2020, având la bază, iniţial, un lot de 410 de pacienţi ce s-au adresat medicului ortodont, având drept motive ale prezentării tulburări de ordin estetic şi funcţional, dintre care au fost selectaţi 56 pacienţi cu malocluzii de clasa a III-a, fără edentaţii sau tratamente protetice. În vederea elaborării diagnosticului, s-a recurs la realizarea examenului clinic şi a examenelor paraclinice: fotografic, studiul de model şi radiologic (radiografie retroalveolară, ortopantomogramă şi teleradiografie de profil), cu ajutorul cărora s-a întocmit fişa de observaţie şi, ulterior, s-a stabilit planul de tratament.

Analiza datelor şi interpretarea rezultatelor s-a realizat cu ajutorul analizei statice efectuate în programul Microsoft Excel, şi, ulterior, exemplificate prin metode grafice.

\section{REZULTATE}

Rezultatele investigaţiilor clinice obţinute în urma examinării pacienţilor din lotul studiat au permis efectuarea unor grafice ce au scos în evidenţă incidenţa anomaliei clasei a III-a Angle.
Trebuie menţionat că, dintre cei 410 pacienţi consultaţi şi trataţi în decursul celor 18 luni, 218 pacienţi (53\%) prezentau anomalie de clasa I Angle, 76 pacienţi (19\%) anomalie de clasa II/1 Angle, 60 pacienţi (15\%) anomalie de clasa II/2 Angle, iar 56 pacienţi (13\%) aveau caracteristicile anomaliei de clasa a III-a Angle.

Pe lotul de 56 de pacienţi cu malocluzii de clasa a III-a Angle, au fost urmărite şi analizate următoarele date:

- sex (fig. 1);

- vârstă (fig. 2);

- mediul de provenienţă (fig. 3);

- factorii etiologici incriminaţi (fig. 4);

- tipuri de anomalii de clasa a III-a Angle şi subtipurile acestora (fig. 5, tabel 1);

- anomaliile dentare izolate asociate (tabel 2);

- testul de retropulsie (fig. 6);

- OPG: unghiul mandibular (fig. 7);

- teleradiografie de profil - unghiul FMA (analiza Tweed), SNA, SNB, ANB (fig. 8, fig. 9);

- modalităţile de tratament în funcţie de aparatul ortodontic utilizat (fig. 10).

Analiza datelor din figurile 1,2,3 arată, pe lotul studiat, o frecvenţă mai ridicată a anomaliilor de clasa a III-a la sexul masculin, adolescenţi (14-18 ani), din mediul urban.
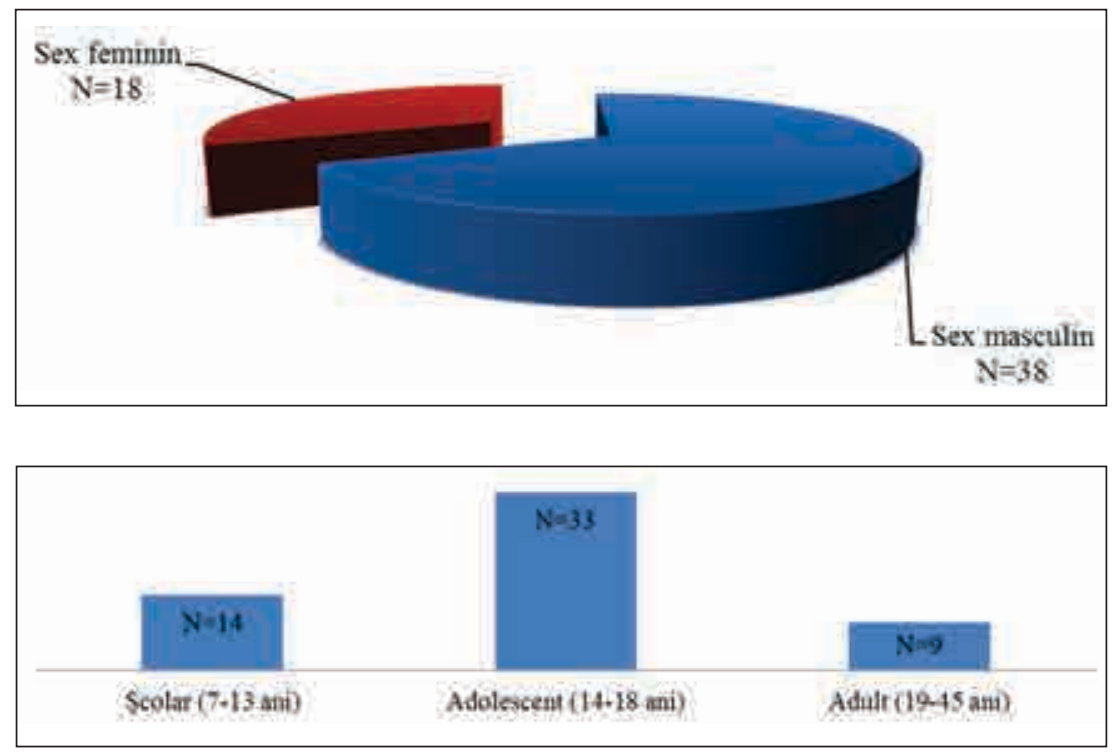

FIGURA 1. Distribuția anomaliilor de clasa a III-a Angle în funcție de sex

FIGURA 2. Distribuția anomaliilor de clasa a III-a Angle în funcție de vârstă

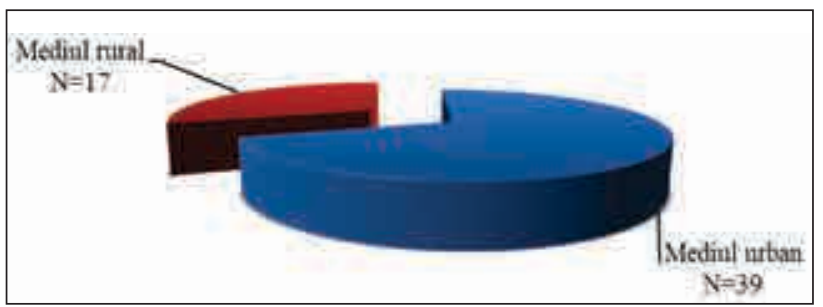

FIGURA 3. Distribuția anomaliilor de clasa a III-a Angle în funcție de mediul de proveniență 


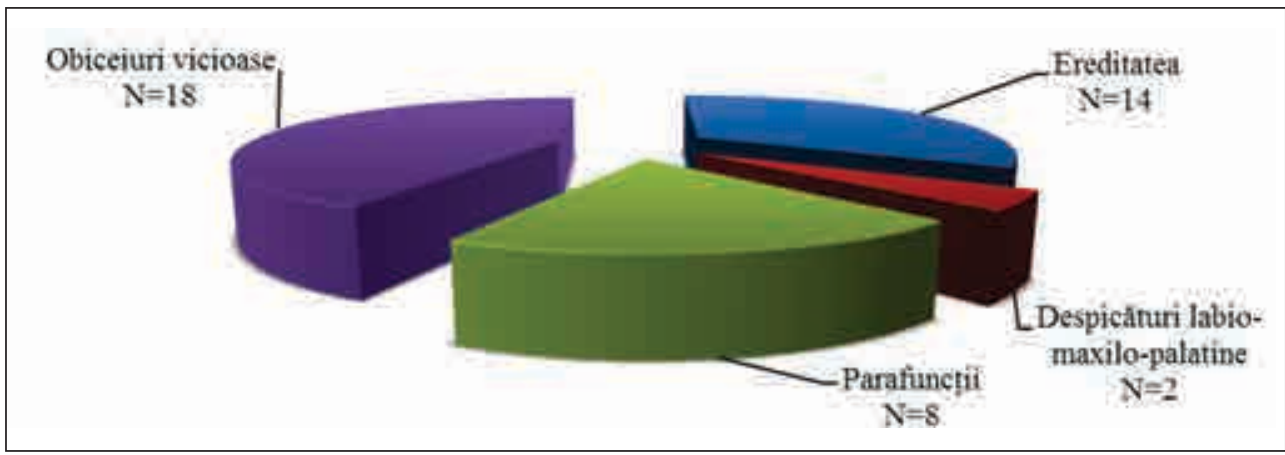

FIGURA 4. Distribuția anomaliilor de clasa a IIl-a Angle în funcție de factorii etiologici incriminați

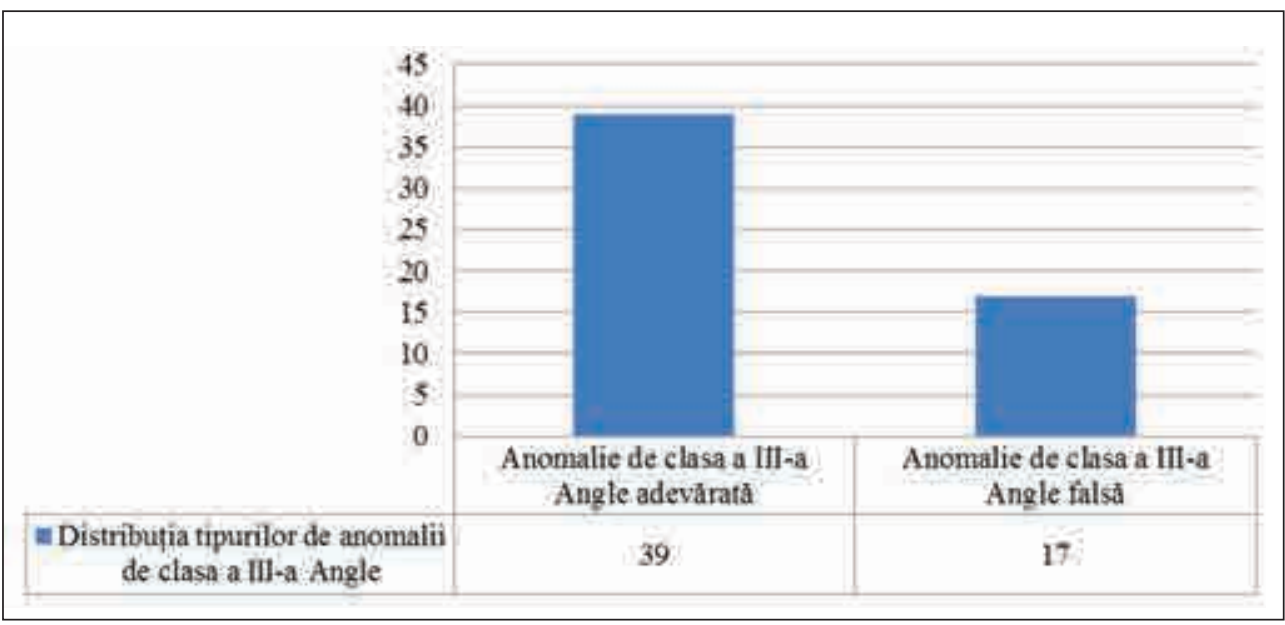

FIGURA 5. Distribuția tipurilor de anomalii de clasa a III-a Angle

În urma analizei grafice, din lotul de 56 cazuri, antecedentele personale patologice ale acestora relevă prezenţa a 4 factori etiologici importanţi, repartizaţi astfel: la 14 pacienţi se remarcă influenţa genetică, 2 pacienţi prezintă despicături labiomaxilo-palatine, 8 pacienţi prezintă parafuncţii (ticuri), iar cei mai mulţi dintre aceştia, şi anume 18 pacienţi, prezintă obiceiuri vicioase (muşcarea buzei, obrazului, deglutiţie infantilă) (Fig. 4).

Din totalul de 56 cazuri clinice de anomalii dento-maxilare clasa a III-a Angle, 39 cazuri au prezentat anomalii dento-maxilare clasa a III-a Angle subdiviziunea 1 (prognatism adevărat), iar 17 cazuri au prezentat anomalii dento-maxilare clasa a III-a Angle subdiviziunea 2 (prognatism fals) (Fig. 5).

TABEL 1. Distribuția tipurilor de anomalii de clasa a III-a Angle după tipul de dentiție

\begin{tabular}{|l|c|c|}
\hline $\begin{array}{l}\text { Tipuri de anomalie de clasa a III-a } \\
\text { Angle }\end{array}$ & $\begin{array}{c}\text { Dentiție } \\
\text { mixtă }\end{array}$ & $\begin{array}{c}\text { Dentiție } \\
\text { permanentă }\end{array}$ \\
\hline Prognatism mandibular adevărat & 6 & 3 \\
\hline $\begin{array}{l}\text { Prognatism mandibular funcțional } \\
\text { de natură condiliană }\end{array}$ & 8 & 2 \\
\hline $\begin{array}{l}\text { Prognatism mandibular funcțional } \\
\text { de natură cuspidiană }\end{array}$ & 10 & 4 \\
\hline
\end{tabular}

\begin{tabular}{|l|c|c|}
\hline $\begin{array}{l}\text { Tipuri de anomalie de clasa a III-a } \\
\text { Angle }\end{array}$ & $\begin{array}{c}\text { Dentiție } \\
\text { mixtă }\end{array}$ & $\begin{array}{c}\text { Dentiție } \\
\text { permanentă }\end{array}$ \\
\hline $\begin{array}{l}\text { Micrognatism maxilar prin } \\
\text { despicături labio-maxilo-palatine }\end{array}$ & 7 & 4 \\
\hline $\begin{array}{l}\text { Retrognatism maxilar prin } \\
\text { anodonții }\end{array}$ & 9 & 3 \\
\hline Total & 40 & 16 \\
\hline
\end{tabular}

În tabelul 1, este prezentată distribuţia tipurilor de anomalie de clasa a III-a Angle (adevărat, fals, de conducere forţată) raportate la tipul de dentiţie, iar tabelul 2 arată anomaliile dentare izolate asociate cu malocluziile de clasa a III-a.

TABEL 2. Distribuția anomaliilor de clasa a III-a Angle asociate $\mathrm{cu}$ alte anomalii dentare izolate

\begin{tabular}{|l|c|c|}
\hline Anomalia dento-maxilară & Forma clinică & Nr. cazuri clinice \\
\hline De număr & Anodonţie & 15 \\
\hline De volum & Microdonţie & 1 \\
\hline De formă & Geminaţie & 1 \\
\hline De poziție & De grup & 2 \\
\hline De sediu & $\begin{array}{l}\text { Ectopie } \\
\text { Incluzie }\end{array}$ & 3 \\
\end{tabular}

În urma realizării testului de retropulsie, din numărul total de cazuri cu anomalie clasa a III-a Angle, la 10 cazuri răspunsul a fost pozitiv, la 9 


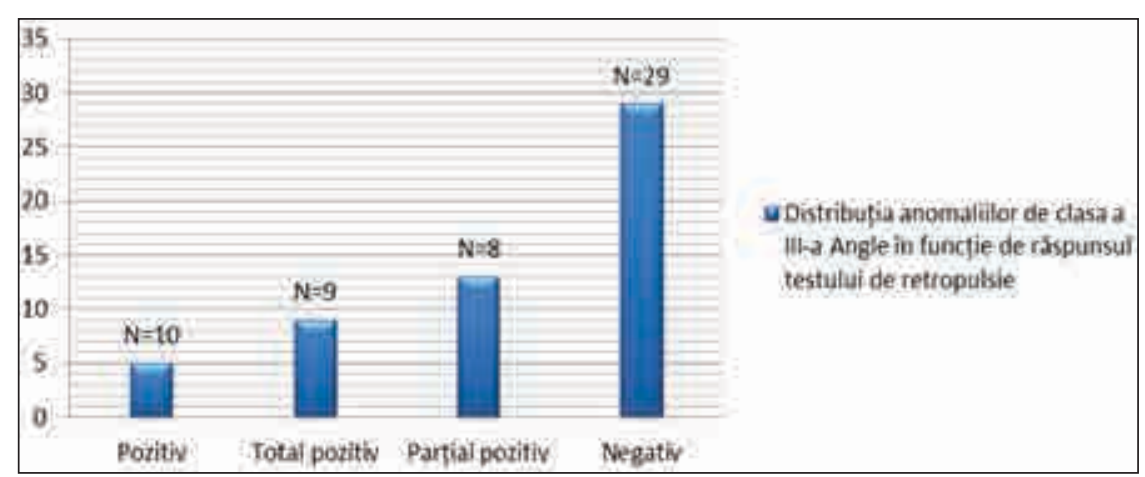

FIGURA 6. Distributia anomaliilor de clasa a III-a Angle în funcție de răspunsul testului de retropulsie
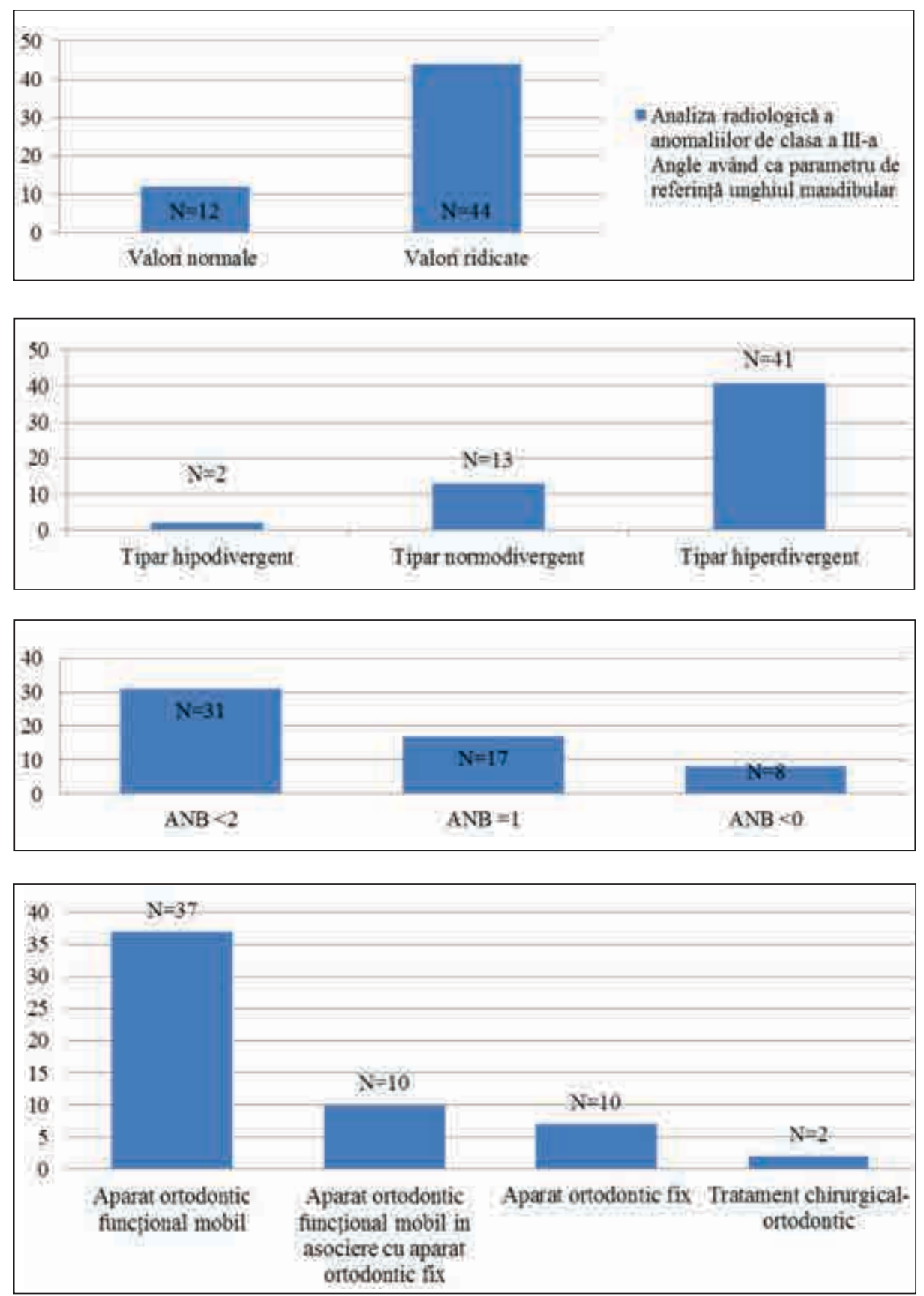

FIGURA 7. Analiza radiologică a anomaliilor de clasa a III-a Angle având ca parametru de referință unghiul mandibular

FIGURA 8. Distribuția

anomaliilor de clasa a III-a Angle având ca parametru de referință unghiul FMA (analiza Tweed)

\section{FIGURA 9. Analiza}

teleradiografică a anomaliilor de clasa a III-a Angle având ca parametru de referință unghiul ANB

\section{FIGURA 10. Distributia} modalităților de tratament în functiie de aparatul ortodontic utilizat cazuri - răspuns total pozitiv, la 8 cazuri - răspuns parţial pozitiv, iar majoritatea cazurilor, şi anume 29, prezintă răspuns negativ (ca urmare a prezenţei angrenajului invers şi ocluziei inverse frontale) (Fig. 6).
Analiza examenelor radiografice (ortopantomogramă şi teleradiografie de profil) a arătat valori ridicate ale unghiului goniac (la 44 pacienţi) (fig. 7), cu tipar de dezvoltare hiperdivergent (unghi FMA mai mare de $30^{\circ}$ la 41 pacienţi - 
fig. 8) şi valori ridicate ale unghiului ANB (la 31 pacienţi) (fig. 9).

În funcţie de metoda de tratament aleasă, dintre cei 56 de pacienţi cu anomalie de clasa a III-a Angle, 37 pacienţi au beneficiat de aparat ortodontic funcţional mobil, 10 pacienţi de aparat ortodontic mobil în asociere cu aparat ortodontic fix, 7 pacienţi de aparat ortodontic fix, iar 2 pacienţi au beneficiat de tratament chirurgical-ortodontic (Fig. 10).

\section{DISCUȚII}

Adresabilitatea pentru tratamentul anomaliilor dento-maxilare de clasa a III-a Angle este mai ridicată în rândul pacienţilor adolescenţi, de sex masculin, din mediul urban. Şi aspectul clinic al prognatismului mandibular adevărat (scheletal) influenţează pacienţii, astfel încât acesta se regăseşte într-o mai mare proporţie comparativ cu malocluziile de clasa a III-a Angle determinate de migrognatismul maxilar determinat de despicături labio-maxilo-palatine sau de anodonţiile de incisivi laterali sau premolari secunzi maxilari $(18,19)$.

Investigaţiile radiologice folosite pentru diagnostic şi predicţia de creştere, de tipul teleradiografiei de profil, evidenţiază unghiul FMA mărit, caracteristic tiparului hiperdivergent, $\mathrm{cu}$ valori scăzute ale unghiului SNA, valori crescute ale unghiului SNB şi valori negative ale unghiului ANB $(11,12,20)$.

În funcţie de metoda de tratament aleasă, cea mai mare nevoie de tratament este adresată anomaliilor dento-maxilare de clasa a III-a Angle, ca urmare a expresiei clinice caracteristice şi a tulbură-

\section{BIBLIOGRAFIE}

1. Laura Mitchell. An introduction to orthodontics. Oxford University Press, United Kingdom, 2013; pag. 41.

2. Proffit WR, Fields HW, Sarver DM, Contemporary Orthodontics, Mosby Inc, 2007.

3. Graber TM. Orthodontics: Current Principles and Techniques, Third Edition. Mosby Inc., St. Louis, 2000.

4. Moyers RE, Krogman WM. Cranio-facial Growth in Man. Pergamon Press Inc., Oxford, 1971.

5. Graber TM, Rakosi T, Petrovic AG. Dentofacial Orthopedics with Functional Appliances. University of Michigan, Mosby, 1997.

6. McNamara JA, Brudon WL. Introduction and overview. Orthodontics and dentofacial orthopedics. Ann Arbor: Needham Press, Inc; 2001.

7. Battagel JM. The aetiological factors in Class III malocclusion. The European Journal of Orthodontics 1993;15 (5):347-70.

8. Costa Pinho TM, Ustrell Torrent JM, Correia Pinto JG. Orthodontic camouflage in the case of a skeletal class III malocclusion. World $\mathrm{J}$ Orthod. 2004;5(3):213-23. rilor consecutive asociate, şi în special pacienţilor adolescenţi, în perioada de creştere pubertară aceştia beneficiind, de cele mai multe ori, de tratament ortodontic cu aparat ortodontic funcţional mobil sau fix, asociat $\mathrm{cu}$ forţe extraorale şi intraorale $(8,17,21,22)$.

\section{CONCLUZII}

Complexitatea clinicii anomaliilor dento-maxilare de clasa a III-a Angle rămâne o provocare pentru medicii ortodonţi, ca urmare a manifestărilor dentare, scheletale, estetice şi funcţionale. În funcţie de particularităţile fiecărui caz clinic, pentru evaluarea unui diagnostic corect şi stabilirea unui plan eficient de tratament, se realizează investigaţii clinice şi paraclinice pe baza cărora se stabileşte metoda de tratament (profilactic, preventiv, curativ) cât mai eficientă şi cu rezultate cât mai stabile în timp, un tratament individualizat, cu rezultate estetice favorabile şi în asociere cu statusul psihosomatic şi social al pacientului.

Tratamentul de elecţie este rezultatul colaborării dintre medicul specialist ortodont şi medicul specialist de chirurgie ortognatică, care vor decide dacă pacientul va beneficia de următoarele posibilităţi de tratament: tratament ortodontic de prevenire a apariţiei sau agravării anomaliei în perioada de creştere posturală (tratament profilactic şi interceptiv), tratament de camuflare a anomaliei de clasa a III-a Angle (tratament ortodontic) sau tratament de repoziţionare a întregului complexului osos, muscular şi dentar (tratament chirugicalortodontic).

Conflict of interest: none declared Financial support: none declared

9. Decusară M, Şincar DC, Popa GV, Rusu-Negraia M. The importance of interceptive orthodontic treatment in dento-maxillary abnormalities caused by vicious habits. Analele Universității "Dunărea de Jos" Medicină, 2017;17(2):43-48.

10. Bishara SE. Facial and dental changes in adolescents and their clinical implications. Angle Orthod. 2000;70(6):471-83.

11. Reyes BC, Baccetti T, McNamara JA Jr. An estimate of craniofacial growth in Class III malocclusion. Angle Orthod. 2006;76(4):577-584.

12. Baccetti T, Franchi L, McNamara JA Jr. Growth in the untreated class III subject. Semin Orthod. 2007;13(3):130-142.

13. Guyer EC, Ellis EE, McNamara JA. Components of class III malocclusion juveniles and adolescents. Angle Orthod. 1986, 56(1):7-30.

14. Chan GK-h. Class III malocclusion in Chinese (Cantonese): etiology and treatment. American Journal of Orthodontics and Dentofacial Orthopedics 1974;65(2):152-57. 
15. Ngan P, Moon W. Evolution of Class III treatment in orthodontics. Am J Orthod Dentofacial Orthop. 2015;148(1):22-36.

16. Ngan P, Wei SHY. Early treatment of Class III patients to improve facial aesthetics and predict future growth. Hong Kong Dent $\mathrm{J}$. 2004;1:24-30.

17. De Clerck HJ, Proffit WR. Growth modification of the face: a current perspective with emphasis on Class III treatment. Am J Orthod Dentofacial Orthop. 2015;148(1):37-46.

18. Hardy DK, Cubas YP, Orellana MF. Prevalence of Angle Class III malocclusion: a systematic review and meta-analysis. Open $\mathrm{J}$ Epidemiol. 2012;2:75-82.

19. Rakosi T, Schilli W. Class III anomalies: a coordinated approach to skeletal, dental, and soft tissue problems. J Oral Surg. 1981; 39(11):860-870
20. Moon YM, Ahn SJ, Chang YI. Cephalometric predictors of long-term stability in the early treatment of Class III malocclusion. Angle Orthod. 2005;75(5):747-753.

21. Ngan P. Early treatment of Class III malocclusion: is it worth the burden? Am J Orthod Dentofacial Orthop. 2006;129(4):S82-S85.

22. Mandall N, Cousley R, DiBiase A, et al. Early class III protraction facemask treatment reduces the need for orthognathic surgery: a multi-centre, two-arm parallel randomized, controlled trial. J Orthod. 2016;43(3):164-175. 